\title{
O LIBERALISMO ECONÔMICO E AS PRÁTICAS DE SEGURANÇA: O “AVESSO” DAS DEMOCRACIAS LIBERAIS
}

\author{
ECONOMIC LIBERALISM AND SECURITY PRACTICES: \\ THE “REVERSE” OF LIBERAL DEMOCRACIES
}

\author{
Ricardo Manoel Oliveira Morais \\ Universidade Federal de Minas Gerais - UFMG - (Belo Horizonte, MG, Brasil) \\ Adriana Campos Silva \\ Universidade Federal de Minas Gerais - UFMG - (Belo Horizonte, MG, Brasil)
}

Recebimento: 5 jul. 2017

Aceitação: 31 ago. 2017

Como citar este artigo / How to cite this article (informe a data atual de acesso / inform the current date of access):

MORAIS, Ricardo Manoel Oliveira; SILVA, Adriana Campos. O liberalismo econômico e as práticas de segurança: o “avesso" das democracias liberais. Revista da Faculdade de Direito UFPR, Curitiba, PR, Brasil, v. 62, n. 3, p. 221-242, set./dez. 2017. ISSN 2236-7284. Disponível em: <http://revistas.ufpr.br/direito/article/view/53720>. Acesso em: 21 dez. 2017. DOI: http://dx.doi.org/10.5380/rfdufpr.v62i3.53720.

\section{RESUMO}

Este artigo tem por objetivo analisar alguns dos paradoxos relacionados ao liberalismo econômico e os discursos de segurança a ele subjacentes que, embora neguem os princípios basilares das democracias modernas, passam a fazer parte delas. Neste exame o principal eixo teórico será o pensamento de Foucault. Primeiramente será apontado que o liberalismo econômico, na análise foucaultiana, tem como premissa uma essência antropológica de ser humano, pois assume como ponto de partida que a liberdade só floresce na ausência de constrangimentos. Na medida em que esta premissa metafísica se impõe às instituições das democracias modernas, alguns desdobramentos se colocam. Surge a noção de que o papel das instituições democráticas é o de proporcionar liberdade. Entretanto, só pode haver liberdade se houver segurança. Assim, impõe-se um paradoxo: as democracias têm como telos a liberdade, mas a liberdade pressupõe medidas de segurança (na guerra ao terror, por exemplo) que negam tanto os preceitos democráticos quanto a própria liberdade.

\section{PALAVRAS-CHAVE}

Liberalismo econômico. Segurança. Liberdade. Democracias liberais.

\begin{abstract}
This article aims to analyze some of the paradoxes related to economic liberalism and the underlying security discourses that, although denying the basic principles of modern democracies, become part of them. In this exam the main theoretical axis will be Foucault's thought. First, it will be pointed out that economic liberalism, in Foucaultian analysis, has as its premise an anthropological essence of being human, since it assumes as its starting point that freedom only flourishes in the absence of constraints. As this metaphysical premise imposes itself on the institutions of modern democracies, some developments are posed. Arises the notion that the role of democratic institutions is to provide freedom. However, there can be freedom only if there is security. Therefore, a paradox is imposed:
\end{abstract}


democracies have freedom as their telos, but freedom presupposes security measures (in the war on terror, for example) that deny both democratic precepts and freedom itself.

\section{KEYWORDS}

Economical liberalism. Security. Freedom. Liberal democracies.

\section{INTRODUÇÃO}

O objetivo deste artigo é analisar, criticamente, algumas das contradições constituídas pela conexão entre o liberalismo econômico (na análise foucaultiana) e as democracias modernas, tendo em vista que a concepção de liberdade assumida por estes modelos pressupõe a adoção de práticas de segurança que, paradoxalmente, negam os princípios tanto democráticos quanto de liberdade. Nesta análise a principal linha analítica será o curso de Michel Foucault no Collège de France, Nascimento da Biopolítica e Segurança, de 1979. Conforme será examinado, o liberalismo econômico é muito mais que uma mera doutrina econômica, na medida em que supõe que os processos econômicos não só são capazes de se autorregular, mas que a não intervenção neste domínio irá levar a sociedade ao pleno equilíbrio. Todavia, o que estaria implicado nesta premissa é um dogma mais profundo, o de que haveria um determinante antropológico econômico e liberal no ser humano.

Primeiramente será examinada a questão do liberalismo na perspectiva de Michel Foucault, bem como os desdobramentos de suas premissas a fim de que, em seguida, sejam analisados os paradoxos aos quais esses desdobramentos levam. Neste sentido, ainda que algumas referências sejam feitas ao pensamento liberal, o cerne deste artigo é o exame foucaultiano do tema. No liberalismo, o ser humano seria livre “por natureza” ou “por essência”, razão pela qual todos os humanos que já existiram e que existirão possuiriam uma “vontade natural” de exercer uma liberdade, e o farão desde que não haja constrangimentos à sua essência. Neste sentido, a essência humana só pode ser realizada se se permitir que a liberdade negativa floresça, devendo tanto a sociedade quanto as instituições políticas evitarem a aplicação de constrangimentos desnecessários aos seus membros. Com isso, é possível inferir que um regime ou uma ordem política que seja considerada boa ou democrática deve, antes de tudo, respeitar a essência liberal do ser humano.

Todavia, e neste ponto serão examinadas as reflexões de Thomas Lemke, Opitz e Krasmann, há uma dificuldade em não aplicar constrangimentos, o que significa que há um impasse quanto à possibilidade de se viabilizar um campo no qual a essência do ser humano possa se manifestar. Isso porque a manifestação da liberdade pressupõe, por um lado, que a liberdade não pode sofrer restrições. Entretanto, há aqueles indivíduos que no exercício de sua liberdade restringem a liberdade de outros. Além disso, para que a liberdade floresça, deve haver segurança, que será garantida por 
medidas de segurança. Só se pode ser realmente livre quando os indivíduos se sentem seguros para exercer sua liberdade. E se o respeito à essência liberal é a base de um regime democrático, tanto a ausência de coerção quanto as medidas de segurança passam a fazer parte dos modelos de democracia. Com isso, serão analisadas algumas práticas de segurança que, ao mesmo tempo que fazem parte das democracias liberais, negam totalmente os preceitos democráticos, tal como as medidas de exceção empregadas na guerra ao terror.

\section{LIBERALISMO ECONÔMICO E LIBERDADE}

Embora o liberalismo econômico seja tratado como uma simples doutrina, uma corrente teórica da economia ou um regime de saber que defende a limitação das intervenções do ente estatal nas relações econômicas, ele deve ser analisado como um fenômeno que vai muito além disso. Isso porque o liberalismo parte do pressuposto de que a abstenção da atuação do Estado nas relações econômicas levaria a sociedade a um status de equilíbrio social, tendo em vista que os processos econômicos seriam capazes de se autorregular e, com isso, universalizar as leis da economia (do “mercado”) a outras instâncias sociais, de modo a estabelecer o perfeito equilíbrio social. Já que as leis da economia poderiam irradiar o seu equilíbrio a outras esferas, isso significa que o papel de um governo democrático é tão somente o de se abster em relação ao "mercado". Isto é, como se “democracia” e "respeito às leis de mercado” fossem sinônimos, uma vez que o papel da democracia é realizar as potencialidades do ser humano e isso somente poderia ser feito por meio da abstenção do Estado nos assuntos econômicos.

A própria liberdade política poderia ser colocada como uma decorrência da liberdade econômica, ou seja, se esta for assegurada, necessariamente aquela será alcançada. Sendo o capitalismo competitivo e a organização econômica o que viabiliza a liberdade econômica, isso significa que ela produz, necessariamente, a liberdade política, na medida em que tal modelo seria capaz de separar (não apenas em abstrato) o poder econômico do poder político. Nos termos de Friedman, existem fortes evidências históricas que demonstram a relação entre liberdade política e livre mercado. Uma vez que o Ocidente viveria em um estado de liberdade, as pessoas tenderiam a esquecer o quão limitado seria o espaço de tempo e a parte do mundo onde há liberdade política, sendo a tirania, a servidão e a miséria, o estado típico da humanidade. A liberdade política só emergiria na contemporaneidade (assim como emergiu na era clássica e em Roma), e efetivaria a potencialidade liberal humana, com o mercado livre e o desenvolvimento das instituições capitalistas (FRIEDMAN, 1992, p. 8-10). 
O liberalismo econômico, na medida em que adota como pressuposto um ideal acerca da realidade (que é o de que as leis e processos econômicos sejam deixados livres para a sociedade alcançar algo próximo ao que um grego chamaria de eudaimonia), carrega em sua formulação uma “tese antropológica”, uma concepção essencialista do ser humano. Se as relações econômicas são relações entre os indivíduos numa instância universal denominada mercado que, por sua vez, possui leis próprias que devem ser captadas pelos economistas (que são os analistas das leis universais da liberdade) de forma objetiva, essas leis do mercado, por serem absolutas, devem necessariamente ter como pano de fundo o dogma de que os indivíduos se comportam da mesma forma, com o mesmo ânimo e de acordo com os mesmos padrões (PIZZORNO, 1989, p. 236; SAFATLE, 2015, p. 193200) $)^{1}$. Foucault (2008, p. 78-80) expõe que é como se o ser humano fosse marcado por natureza por uma essência liberal econômica, o que é o elemento que deixa patente que o liberalismo e o neoliberalismo vão muito além de uma mera doutrina ou corrente econômica. É como se a "natureza” tivesse querido que o ser humano "[...] fosse entregue à atividade econômica que é a da produção e da troca. [...] a natureza de certa forma lhe ditou por baixo do pano, de certa forma deixou impressas nas disposições das coisas, da geografia, do clima, etc.”.

E quais são essas disposições? Primeiro, que os homens possam, individualmente, ter uns com os outros relações de troca baseadas na propriedade, etc., e é isso, essa prescrição da natureza, esse preceito da natureza, que os homens vão retomar como obrigações jurídicas, e assim teremos o direito civil (FOUCAULT, 2008, p. 79).

Conforme expõe Lemke (2011, p. 45), “Foucault concebe o liberalismo não como uma teoria econômica ou ideologia política, mas como uma arte específica de governar seres vivos”. Além disso, ressalta que o "Liberalismo introduz uma racionalidade de governo que se difere tanto dos conceitos medievais de dominação quanto da razão de estado moderna: a ideia de uma natureza da sociedade que constitui a base e o limite da prática governamental”.

Como um grande expoente do neoliberalismo, Friedman (1992) expõe que a liberdade econômica seria um fim em si mesma, na medida em que os arranjos econômicos devidos poderiam propiciar uma sociedade livre (ou seja, propiciar a liberdade em todos os seus aspectos). Neste sentido, a liberdade econômica seria o componente da liberdade em um sentido mais amplo, bem como uma condição de possibilidade para que se alcance a liberdade política. A frase de Margaret

\footnotetext{
${ }^{1}$ Safatle (2015) expõe que o neoliberalismo é uma reformulação do modelo liberal de gestão social, produção de formas de vida e de sujeitos (homo oeconomicus) que levou ao processo de acumulação pela expropriação absoluta do trabalho. Constituiu-se um modelo generalizável, o "ideal empresarial de si”, cuja introjeção fez com que tudo fosse pensado pela lógica de mercado. Com isso, o neoliberalismo irradia efeitos de verdade com um fundo "essencialista”, devendo todos agir segundo esse padrão essencial e normalizador.
} 
Thatcher "Economics are the method. The object is to change the heart and soul" (SAFATLE, 2015, p. 193) demonstra claramente a "tese antropológica” que subjaz ao liberalismo econômico, assim como demonstra qual seria a ciência por excelência do modelo liberal, a economia. Isso porque, se existem leis que podem ser apreendidas por meio de uma aplicação sistemática de uma determinada racionalidade, e se essas leis têm como pressuposto uma essência econômica do ser humano, deve haver, necessariamente, uma ciência que seja capaz de apreender todas essas leis absolutas e, por conseguinte, eternas.

Assim, podem-se colocar quatro questões: 1) em que consistiria essa essência liberal do ser humano? 2) sendo o conhecimento dessa essência condição de possibilidade para se assegurar a liberdade, de que modo ela poderia ser desvelada? 3) na busca científica pela apreensão dessa essência, quais máximas antropológicas poderiam ser universalizadas para que a sociedade alcance a plenitude? 4) seria possível realizar o modelo liberal e quais as consequências possíveis disso?

No que diz respeito à primeira questão, deve-se frisar que o ser humano seria um ser livre “por natureza” ou "por essência”. Neste sentido, todos os seres humanos que já existiram e que existirão possuiriam uma “vontade natural” de exercer a liberdade, e o farão desde que não existam constrangimentos. Nos termos de Pizzorno (1989, p. 236), “Os indivíduos estão sempre lá, cada um idêntico a si mesmo em seu tempo, com suas vontades e suas decisões. Quando um determinado constrangimento não é empregado, o indivíduo é socialmente livre”. Neste sentido, a essência humana só pode ser realizada se se permitir que uma espécie de "liberdade negativa” floresça, devendo a sociedade evitar aplicar constrangimentos desnecessários aos seus membros.

Assim, o ser humano é um ser que anseia por uma libertação em face a todos os constrangimentos, aspiração esta que decorre de sua essência. Nesse sentido, se a liberdade é a essência, o ser humano deve buscá-la a todo instante. Pode-se, a partir disso, inferir que a "vontade de potência” se traduziria, verdadeiramente, em uma “vontade de libertação” dos constrangimentos². Vale dizer que se o ser humano possui tal essência, esta é uma marca que antecede a todas as relações que ele irá constituir na vida em comunidade e as relações apenas se estabelecem a partir dessa vontade de libertação. E, como mencionado, se a liberdade econômica é capaz de, por si só, gerar todas as outras formas de liberdade, isso significa que o ser humano é, antes de tudo, um ser econômico, ou seja, ele é um homo oeconomicus. Um ser que, sendo o senhor de si mesmo (o

\footnotetext{
${ }^{2}$ O próprio Foucault (2008, p. 85) afirma que o neoliberalismo é uma doutrina naturalista por operar com a dimensão da liberdade. Para ele, em $A$ verdade e as formas jurídicas, noções de absoluto constituiriam uma vontade de potência, e a absolutização da essência econômica não é uma exceção. Foucault (a partir do pensamento de Nietzsche) defende que um absoluto é o que decorre de um “instinto” de poder, ou “vontade de poder”.
} 
empresário de si), deve ser analisado para que sirva de grade de inteligibilidade não apenas da atividade econômica, mas de todo o real (FOUCAULT, 2008, p. 310-311). E, para que a essência humana não seja perdida, o slogan liberal laissez-faire deve ser efetivado.

Os constrangimentos que desvirtuam a essência econômica humana poderiam advir tanto de instituições políticas, como um Estado ou um governo interventor (interventor compreendido como “constrangedor”), quanto de outros seres humanos. Em outras palavras, os constrangimentos poderiam advir de uma gama de fontes, desde relações humanas em um nível pessoal (familiar, amizade, trabalho) até macrorrelações ou instituições potencialmente corruptoras dessa vontade por libertação (FOUCAULT, 2008, p. 310-311). Mais uma vez, o ser humano deve estar livre de eventuais constrangimentos, caso contrário não irá efetivar as suas potencialidades de "indivíduo livre por natureza”. Ainda que existam eventuais modelos de instituições políticas ou entidades sociais nas macrorrelações, a tarefa destas organizações é de tão somente garantir a liberdade econômica. Neste sentido, nem mesmo as leis devem retirar parcelas dessa liberdade, pois isso seria ceifar a natureza humana. Conforme Foucault (2008, p. 61-61) explicita no Nascimento da Biopolítica, o exercício do poder político passa a ter que obedecer a interesses individuais.

Assim, partindo do pressuposto de que o indivíduo é marcado por natureza pela "vontade de libertação", isso implica que o ser humano possui tal essência mesmo antes da vida em comunidade, ou seja, mesmo antes da vida com outros seres humanos e, seguramente, antes da vida política. A vida em comunidade e, sobretudo, na esfera política, apenas iria comprovar em um nível coletivo aquilo que no nível individual e privado já se tem como dado ontológico: que o ser humano, para que seja humano, deve estar radicalmente desimpedido de toda e qualquer imposição externa, o que leva à segunda questão. Quanto a esta, que se questiona sobre a forma como a essência liberal poderia ser desvelada, a resposta estaria diretamente atrelada à primeira: tal natureza apareceria na medida em que o homem deixa de ser coagido.

Com base nestes imperativos, a natureza humana deve ser analisada e compreendida, podendo-se com isso extrair leis universais por meio de um exame sistemático e neutro ${ }^{3}$ dos dados econômicos que emanam da ação livre de coação. Todavia, uma vez que o ser humano só pode ser submetido a um exame sistemático se ele for tomado como um objeto de análise por outros seres humanos, mesmo que sua essência anteceda a vida em comunidade e as relações sociais, ela só pode

\footnotetext{
${ }^{3}$ A questão da neutralidade é, para Foucault, um artifício de dominação bastante perigoso. Isso porque, como o autor coloca em Em defesa da sociedade, as relações de poder (que são estruturantes da realidade humana) são marcadas por relações de força, razão pela qual não são neutras, assim como não o são os indivíduos que agem na malha do poder. Sempre que um determinado campo de poder arroga para si o status de neutralidade é visando impor os seus interesses, fazendo-os assumir efeitos de verdade.
} 
ser objetivada após o estabelecimento de relações ${ }^{4}$. Se não há como isolar os indivíduos para compreender o seu agir com liberdade (mesmo porque liberdade só faz sentido entre agentes que se relacionam), os “cientistas do liberalismo” devem examinar o meio onde os indivíduos estão inseridos e tentar, nesse meio, reforçar na prática a necessidade teórica da ausência de constrangimentos. E, na medida em que a investigação sobre a essência econômica é travada na modernidade, uma variável a ser considerada no "meio” de análise é o Estado.

Neste sentido, havendo um ente governamental que se projeta para além dos indivíduos e suas microrrelações e que tem como suas principais características a soberania (poder absoluto) e o monopólio da violência ${ }^{5}$ (o poder de coagir), para que a natureza desses indivíduos possa ser compreendida e analisada (visando, com isso, aperfeiçoar cada vez mais o “progresso humano”), esse ente estatal deve ser limitado. Caso contrário, a natureza humana não se desvelará. Logo, deve o ente governamental assumir como forma de governo o não constrangimento da essência liberal humana.

Segundo Offe (1984), a política do Estado capitalista passa a ser definida como um emaranhado de estratégias por meio das quais se tenta criar condições para que cada cidadão seja incluído em relações de troca.

Enquanto cada proprietário conseguir introduzir a sua propriedade em relações de troca, não há razão para o Estado intervir no processo privado de alocação. [...] a estrutura do Estado capitalista só se torna problemática quando não se dá a incorporação das unidades individuais de valor às relações de troca (OFFE, 1984, p. 125-126, grifo do autor).

Neste sentido, "O elo entre as estruturas políticas e as econômicas da sociedade capitalista é, portanto, a forma-mercadoria. A estabilidade de cada uma dessas estruturas depende da universalização da forma-mercadoria” (OFFE, 1984, p. 126). Assim, como os indivíduos estão inseridos no campo onde podem exercer a sua liberdade natural - o campo econômico - resta ao governo a abstenção.

Nos termos de Foucault, em Segurança, território, população, na medida em que o Estado é o alvo das diretrizes abstencionistas do liberalismo, deve-se esclarecer que ele não surge na modernidade como continuação das práticas de salvação medievais. O Estado moderno passa a

\footnotetext{
${ }^{4}$ É necessário frisar que o sujeito é, para Foucault, constituído por relações de poder, tema por ele explorado em História da sexualidade I e Leçons sur la volonté de savoir. Tendo em vista que ele critica os absolutos, analisando-os a partir das relações de poder, o mesmo deve ser feito com o sujeito. São as relações de poder que constituem os sujeitos e a realidade humana, não se pode compreender o humano como um dado natural. Quando se coloca que o neoliberalismo pressupõe uma essência de sujeito, isto seria um dos alvos da crítica foucaultiana.

${ }^{5}$ Acerca do monopólio estatal da violência, Weber (1982) conceitua o Estado como uma associação compulsória que organiza a dominação, o espaço privilegiado da política, sendo esta a participação no poder e a possibilidade de influir em sua distribuição, entre Estados e entre os grupos de um Estado. Se o Estado organiza a dominação, ele deve monopolizar a violência e nela se fundamentar e, para que se constitua nestes termos, deve ser autônomo e se projetar para além da sociedade, mas se mantendo aberto a ela (sob pena de ser autoritário).
} 
abarcar uma gama de práticas e dispositivos difusos e descontínuos historicamente e, ainda que não seja uníssono, é considerado como tal devido às teorias unificadoras que geram efeitos de verdade a partir do final do medievo. Esta entidade artificialmente unificada toma corpo em organizações de governo específicas: 1) o mercantilismo: mais que uma doutrina econômica, foi a organização política da produção e dos circuitos comerciais voltados para o enriquecimento e acumulação do Estado, que deveria se fortalecer pela promoção do crescimento populacional e da permanência na concorrência econômica internacional; 2) o Estado polícia: razão de Estado que visa à gestão interna das densas demografias urbanas que decorrem do aumento populacional mercantilista; 3) o aparelho diplomático-militar permanente: visa manter a pluralidade de Estados e conservar o equilíbrio internacional. Essas "São três maneiras, solidárias de resto umas das outras, [de] governar de acordo com uma racionalidade que tem por princípio e por domínio de aplicação o Estado” (FOUCAULT, 2008, p. 8). A dificuldade é estabelecer onde a economia como ciência, que irá se sobrepor à política, emerge.

Neste processo de limitação das intervenções estatais o que se buscou foi um regime de saber que pudesse exercer esse papel limitador, bem como apreender as leis universais dos processos econômicos que serviriam de limite à ação governamental, papel que foi assumido pela economia (ADVERSE, 2014, p. 17).

"Economia política": os próprios equívocos da palavra e do seu sentido naquela época
indicam aliás de que se tratava fundamentalmente, pois se vocês sabem que a expressão
"economia política”, vocês a vêem, entre 1750 e $1810-1820$, oscilar entre diferentes pólos
semânticos. Ora se trata de visar, através dessa expressão, certa análise estrita e limitada da
produção e da circulação das riquezas. Ora "economia política” entende-se também, de forma
mais ampla e mais prática, todo método de governo capaz de assegurar a prosperidade de
uma nação. E, finalmente, [a] economia política [...] é uma espécie de reflexão geral sobre a
organização, a distribuição e a limitação dos poderes numa sociedade. A economia política,
a meu ver, é fundamentalmente o que possibilitou assegurar a autolimitação da razão
governamental (FOUCAULT, 2008, p. 18-19).

Para este regime de saber, uma vez que o ser humano é naturalmente marcado pela vontade de se libertar dos constrangimentos, os processos humanos (desde que não haja forças externas de ingerência) serão capazes de encontrar o equilíbrio na sociedade, pois a essência humana se projetará para todas as demais esferas. Se a natureza do homem é liberal, disso decorre que os processos humanos são naturalmente capazes de se autorregular, sendo eles que irão constituir o objeto de análise de uma ciência do humano que irá inferir as leis acerca da natureza humana como um todo, uma vez que ela é econômica e aspira por liberdade (SILVEIRA, 2005, p. 99-100). E, conforme Friedman (1992, p. 10-11), tendo em vista que a liberdade política apenas renasce na 
contemporaneidade devido ao surgimento do capitalismo, este modelo seria a condição para a real liberdade política.

Assim, se a natureza do homem antecede a sua vida em sociedade, pode-se dizer que ela estaria contida, antes, em suas relações privadas, ou seja, no nomos do oikos. Além disso, o fato de os processos naturais humanos, desde que não sejam alvos de constrangimentos, levarem necessariamente à efetivação de suas melhores potencialidades, isso significa que se cada indivíduo buscar, individualmente, a sua libertação dos constrangimentos, outra possibilidade não haveria que não o equilíbrio, razão pela qual deve-se deixar buscar a liberdade. Em outras palavras, se a natureza emana do indivíduo isoladamente, tanto a efetivação de sua vontade (egoísta) por libertação, quanto os processos globais, caso não sejam alvos de intervenção, poderão se exprimir em leis universais que podem explicar a essência do homem (e esta pode ser a resposta para o terceiro questionamento). Abraça-se uma espécie de “mão invisível”, no sentido de que se cada um agir conforme seus interesses pessoais de liberdade, sem se preocupar com a liberdade de todos, necessariamente o bem comum será atingido ${ }^{6}$.

A este respeito, Hayek (2010), em O caminho da servidão, expõe que a tentativa de tentar coordenar as atividades econômicas por uma via centralizadora é altamente ineficaz, uma vez que a “concorrência” seria o meio mais eficaz de autorregular o mercado.

A doutrina liberal é a favor do emprego mais efetivo das forças da concorrência como um meio de coordenar os esforços humanos, e não de deixar as coisas como estão. Baseia-se na convicção de que, onde exista a concorrência efetiva, ela sempre se revelará a melhor maneira de orientar os esforços individuais. Essa doutrina não nega, mas até enfatiza que, para a concorrência funcionar de forma benéfica, será necessária a criação de uma estrutura legal cuidadosamente elaborada, e que nem as normas legais existentes, nem as do passado, estão isentas de graves falhas. Tampouco deixa de reconhecer que, sendo impossível criar as condições necessárias para tornar efetiva a concorrência, seja preciso recorrer a outros métodos capazes de orientar a atividade econômica. Todavia, o liberalismo econômico é contrário à substituição da concorrência por métodos menos eficazes de coordenação dos esforços individuais. E considera a concorrência um método superior, não somente por constituir, na maioria das circunstâncias, o melhor método que se conhece, mas, sobretudo por ser o único método pelo qual nossas atividades podem ajustar-se umas às outras sem a intervenção coercitiva ou arbitraria da autoridade. Com efeito, uma das principais justificativas da concorrência é que ela dispensa a necessidade de um "controle social consciente" e oferece aos indivíduos a oportunidade de decidir se as perspectivas de determinada ocupação são suficientes para compensar as desvantagens e riscos que a acompanham (HAYEK, 2010, p. 58).

\footnotetext{
${ }^{6}$ Conforme Friedman (1992), em Capitalism and Freedom, a necessidade de um governo (compreendido aqui como esfera política) emerge da impossibilidade de a liberdade absoluta, no sentido de todos poderem fazer o que bem entenderem, poder existir em uma sociedade. Segundo ele, embora em algumas questões, como a proibição do homicídio, não haja dificuldade em concluir que o governo deva restringir a liberdade, em outras a resposta não é tão óbvia, como nas questões econômicas.
} 
E Hayek vai além. Segundo ele, o “bom uso” da concorrência é um princípio de organização social que exclui outros tipos de coação na vida econômica, admitindo que outros tipos de coação podem auxiliar no funcionamento da concorrência, razão pela qual a ação governamental ainda é necessária (HAYEK, 2010, p. 58-59). Com isso, ao ente governamental caberá apenas a tarefa de assegurar um espaço social onde os indivíduos possam projetar a sua natureza econômica. Logo, o governo deverá estabelecer uma forma de que uns não interfiram na esfera de liberdade natural dos outros, sob pena de a natureza humana e as leis que a regem não se mostrarem. Portanto, sendo o ser humano um indivíduo inserido na razão de Estado liberal, segundo a qual o Estado é limitado por dados "verdadeiros" e naturais que emanam dos processos econômicos, um governo só pode ser considerado democrático se ele for liberal, permitindo que a essência humana se materialize. Isso porque não é a usurpação ou a ilegitimidade que se visa combater, mas o excesso de governo. “[...] se o governo vier a atropelar essa limitação, a violar essas fronteiras que lhe são postas, não será ilegítimo por isso, não terá de certo modo abandonado sua essência, não se verá destituído dos seus direitos fundamentais” (FOUCAULT, 2008, p. 15).

Nesse processo de limitação do agir governamental chegou-se a uma ciência que legitimou não um papel limitador da ação de governo, mas um regime de saber que se coloca como absoluto ante o político (ADVERSE, 2014; SILVEIRA, 2005). O slogan 'laissez-faire' demonstra que a política democrática só existe para respeitar as leis de mercado e possibilitar seu funcionamento natural. Para Silveira (2005), a governamentalidade liberal trata toda e qualquer ação humana (mesmo aquelas supostamente externas às relações econômicas) como escolhas e decisões “de mercado”, sendo o agente um animal de vontade (egoísta) previamente definida, cuja liberdade se determina por leis de mercado. Estando o sujeito moderno inserido na razão liberal, segundo a qual o Estado deve ser limitado pela liberdade econômica, o governo só pode ser considerado democrático se respeitar tais processos naturais. Caso ocorra um desrespeito ao mercado, o governo será, por conseguinte, antidemocrático, pois desrespeita as liberdades e a própria natureza humana. Estabelecese, com isso, uma ligação inseparável entre democracia, liberalismo e economia e instaura-se um imperativo: para que um governo seja democrático, basta que ele obedeça às leis de mercado.

Como expõe Friedman (1992, p. 13-14), por exemplo, a liberdade política teria se manifestado em alguns momentos da história, como na polis grega e na república romana, o que leva a crer que a essência liberal aparece apenas nas condições liberais favoráveis. Mas, segundo ele, o problema básico seria como coordenar as atividades econômicas de um grande número de pessoas, sendo essa uma realidade contemporânea. Assim, existiriam dois modos de coordenar as atividades econômicas de milhões de pessoas: pelo uso da coerção (com o uso de medidas totalitárias) ou pelo 
meio da cooperação voluntária de indivíduos (que seria o mercado). A possibilidade de uma coordenação por meio de uma cooperação voluntária (e, por conseguinte, não totalitária e que respeita a essência liberal humana) se baseia no fato de que ambas as partes se beneficiam da transação econômica, ou seja, a "troca” no “mercado”, caso seja “livre”, viabiliza a coordenação sem a coerção. Assim, na medida em que a "liberdade de troca” é assegurada, o "livre mercado" viabiliza a liberdade de todos os seus agentes. Por exemplo, um consumidor é protegido da coação do vendedor devido à existência de outros vendedores que ofertam o produto. Se o governo assegurar este campo sem nele interferir, ele será democrático. Caso contrário, será tirânico.

Neste sentido, a instância de onde emanarão as máximas liberais às quais o governo deve respeito incondicional é o "mercado”. Se a natureza humana antecede a vida em comunidade, tal natureza estaria presente justamente no momento em que o ser humano busca produzir para suprir as necessidades presentes e acumular para as potenciais necessidades futuras (oikos). Além disso, sendo esta a sua natureza, uma eventual coação no sentido de impor um limite à sua acumulação frente às necessidades futuras apenas deturparia a sua natureza liberal. Com isso, a única ciência capaz de compreender de modo efetivo as leis naturais do homem e impor limites aos constrangimentos para que essas leis possam se desvelar é a economia. Tal ciência, por sua vez, ao estabelecer este campo de atuação será capaz de permear o mercado pela razão e, com isso, aperfeiçoar eventuais corrupções da natureza liberal humana.

Claro que o "livre mercado" não elimina a necessidade de governo, pois este é essencial para determinar as “regras do jogo”. O que o mercado faz é reduzir as questões que devem ser decididas pela esfera política, minimizando o tamanho do governo e a necessidade de sua participação no “jogo”. Se a liberdade é a ausência de coerção, a ausência da atuação governamental na esfera do mercado é, por conseguinte, o meio pelo qual a "liberdade de mercado" possibilitaria a liberdade política. Em outras palavras, retirando a organização econômica do controle do poder político, o mercado, ao ter suas leis respeitadas, eliminaria uma fonte de coação (FRIEDMAN, 1992, p. 15-16).

Sobre a liberdade ante os constrangimentos, assim como a razão, nem todos são capazes de utilizá-la com a mesma destreza. Em outras palavras, alguns indivíduos têm mais clareza dos meios que possibilitarão a sua libertação dos constrangimentos que outros, fazendo com que, embora a efetivação da natureza liberal gere equilíbrio, tal equilíbrio seja marcado por uma desigualdade natural. Cálicles, personagem que debate com Sócrates no diálogo platônico Górgias, certamente aclara eventuais dúvidas acerca do desvelar e das potencialidades da essência natural liberal do homem (PLATÃO, 2011, 481b-522e). Segundo ele, deve-se saber a diferença entre natureza (physis) e lei (nomos), que são dimensões que, embora potencialmente convergentes (o que depende de uma 
série de contingências), são inassimiláveis, regidas por lógicas distintas. Cálicles, ao diferenciar lei e natureza a partir do que entende por indivíduos “superiores” e “mais fortes”, diz que, para a natureza, tudo o que é mais vergonhoso também é pior, ao passo que para a lei nem sempre é assim. Se, na natureza, sofrer uma injustiça (ou uma coação) é pior do que cometê-la, quando se trata do espaço das leis, que são convenções humanas, pode ser que cometer uma injustiça ou um constrangimento seja pior. Devido ao fato de que os homens fracos por natureza estão mais sujeitos a sofrerem coações pela sua inferioridade, uma vez que eles são mais numerosos, eles podem impor leis que lhes sejam mais convenientes, corrompendo a natureza. Devido a isso caberia, a um governo preocupado em fazer a natureza livre do homem reinar, evitar tais situações. Vale notar que Cálicles, provavelmente, foi um dos primeiros teóricos do neoliberalismo econômico.

\section{DEMOCRACIA E AS PRÁTICAS DE SEGURANÇA}

Se a essência antecede a vida em comunidade política, ou seja, se a essência pode e deve ser apreendida por meio do nomos do oikos, isso significa que a natureza humana só pode ser econômica, uma vez que apenas a consolidação das necessidades e constrangimentos biológicos por meio de relações produtivas poderiam propiciar um campo para a manifestação e efetivação da natureza liberal humana. Além disso, se cada um deve buscar individualmente a sua libertação dos constrangimentos e, estando todos inseridos nesta busca individual (mesmo porque a essência parte do indivíduo enquanto individualidade), a sociedade chegaria a um status de plenitude. Para que se alcance este telos, a única via possível seria a liberal, em termos econômicos (nomos do oikos).

Devido a isso, a concepção moderna de governo democrático liberal tende a formar uma ligação, que é assumida como um imperativo absoluto, com a economia, na medida em que a forma liberal de governo é aquela em que o Estado não intervém nos processos de liberdade natural, respeitando-os (ADVERSE, 2014, p. 19). Desse modo, a economia passa a ser a ciência que busca a realização do projeto político democrático que é o de libertar a todos dos constrangimentos e determinações. O mercado se coloca como o lugar privilegiado de manifestação de "leis naturais e universais” da essência humana, onde os processos naturais se fazem notar se não forem empregados meios coercitivos. Assim, será a aptidão do governo em não atropelar as leis de mercado que permite classificá-lo como democrático ou autoritário. O governo democrático não é aquele que respeita direitos, mas aquele que respeita a verdade dos processos econômicos e gera efeitos econômicos positivos ao se abster de governar demais. A economia, por si só, é o saber que basta ao corpo político (FOUCAULT, 2008, p. 20). 
Sendo o mercado o que dita as leis de governo e, por conseguinte, do real, os sujeitos que irão atuar neste espaço abstrato também se revestem da naturalidade do mercado. Em outras palavras, sendo o mercado o local onde os agentes são capazes de, no exercício de sua liberdade, constituir processos que levam ao equilíbrio social, necessariamente os agentes sociais possuem uma "essência econômica”, assim como a sociedade. Ao estabelecer métodos analíticos totalizantes e generalizar as leis dos processos econômicos naturais às demais esferas da sociedade, a economia revelaria uma série de regularidades fáticas que se reproduzem, necessariamente, em função de mecanismos objetivamente inteligíveis. Nos termos do próprio Foucault:

É sempre nesse mesmo projeto de analisar, em termos econômicos, tipos de relação que até então pertenciam à democracia, à sociologia, à psicologia, à psicologia social, é sempre nessa perspectiva que os neoliberais procuram analisar, por exemplo, os fenômenos de casamento e do que acontece com um casal, isto é, a racionalização propriamente econômica que o casamento constitui na coexistência dos indivíduos (FOUCAULT, 2008, p. 336).

A liberdade e todas as relações humanas a ela atreladas passam a ser entendidas como o desempenho no âmbito desses processos. Emerge, nesse contexto, o governo liberal como a forma de ordenação política da verdadeira essência humana.

Deste panorama, alguns fenômenos transcorrem. A geração de efeitos econômicos positivos por meio da ordenação socioestatal abstencionista nos processos do mercado e o progresso econômico como telos fazem da participação democrática algo secundário. Isso porque o objetivo democrático máximo é a libertação dos constrangimentos e a liberdade econômica. Caso certos objetivos democráticos “secundários”, como direitos abstratos, sejam sacrificados, não haveria problemas caso o objetivo político seja alcançado: o não constrangimento em processos regidos pelo nomos do oikos.

Sendo liberalismo e democracia entendidos como sinônimos, outras formulações liberais pós-caliclianas surgirão, como o neoliberalismo alemão (escola de Freiburg) e americano (escola de Chicago), embora as questões levantadas girem em torno do mesmo problema: a liberdade. É necessário esclarecer que, nos termos de Lagasnerie (2013) (em A última lição de Michel Foucault), Foucault diferencia o modelo liberal clássico do que se chama de "neoliberalismo". O liberalismo clássico de Adam Smith, Ricardo e Say, por exemplo, tinha o objetivo de separar e manter a autonomia da política e da economia, ao passo que o neoliberalismo impõe uma subordinação da racionalidade política ao regime de saber econômico. Neste sentido, o argumento do neoliberalismo que fundamenta essa subordinação é o pressuposto de que o mercado e a lógica concorrencial são mais eficazes na manutenção da liberdade e da escolha que a “intervenção estatal”, tal como sustentam Hayek e von Mises. E, ao defenderem essa subordinação, sendo o ser humano um ser de 
relações políticas (um ser político), isso significa que toda a sua essência estaria subordinada ao econômico.

Neste sentido, pode-se dizer que tanto a doutrina neoliberal alemã, quanto a americana, constituíram-se como uma tentativa de reorganizar a governamentalidade em uma coesão social apoiada somente nas leis de mercado, na qual o Estado de Direito seria a garantia do respeito a estas leis por parte da entidade estatal (FONSECA, 2002, p. 231-238). Esta teoria constituiu grades de inteligibilidade para todos os comportamentos humanos, formulando leis “econômicas” que vão muito além das leis de mercado. O sujeito se constitui e é explicado, em sua totalidade, por leis econômicas. “A economia tornou-se uma abordagem capaz, em princípio, de dar conta da totalidade do comportamento humano e econômico para programar a totalidade da ação governamental” (SILVEIRA, 2005, p. 103).

Isso significa, concretamente, que as questões maiores do liberalismo dizem respeito ao modo de se governar os homens, vale dizer, sua preocupação primeira não é traçar os limites da ação governamental tendo em vista a proteção dos direitos individuais, mas engendrar uma tecnologia política que assegure a eficácia do poder do Estado. Dito de outro modo, o liberalismo, na medida em que integra as técnicas de governo, está a serviço do gerenciamento da vida dos homens, tomada tanto em escala individual quanto em escala coletiva (a população). Mas se Foucault insere o liberalismo no quadro mais amplo daquilo que ele denomina de biopolítica, resta saber qual é sua função precisa aí, ou seja, como ele deixa sua marca indelével na governamentalidade moderna (ADVERSE, 2014, p. 18, grifo do autor).

Justamente nesse sentido Lemke (2011, p. 44-45) assevera que o liberalismo não seria uma simples ideologia econômica. Mais do que isso, pode-se dizer que o liberalismo é uma forma de metafísica que, assim como outras formas de metafísica, tende a colonizar a existência de modo a efetivar projetos em dissonância com o real. Por conseguinte, o conceito de liberalismo configura um regime produtor de exercícios de poder no qual a razão de Estado moderna propõe uma artificialidade soberana laica que transfere a onipresença do Deus medieval para os pressupostos liberais e teorias soberanas. "Com os Fisiocratas e a economia política, a natureza reaparece como um ponto de referência para a ação política [...]”, mas não como uma ordem criacionista ou cosmológica, mas como aquilo que envolverá a sociedade civil de modo a limitar o monstro do Estado (LEMKE, 2011, p. 45).

Fica claro que, por mais que essa emergência do liberalismo tenha se instaurado como a possibilidade de realização do indivíduo que é livre, já que o Estado (ou outros potenciais agentes constrangedores) não intervém, as práticas de governo demonstram outra situação. Na genealogia desse modelo, não se constata um direito fundamental do indivíduo como sujeito soberano e livre das arbitrariedades do Estado. A própria emergência do liberalismo ocorre no bojo do problema da 
efetividade do exercício de poder, informado por técnicas de condução populacional. Isto é, o regime de saber liberal é assumido como verdade em um momento que se buscam novas formas de governo (PIZZORNO, 1989, p. 240).

Segundo Adverse (2014), tendo o neoliberalismo se constituído no âmago desta cristalização de modos de governar pessoas, ao contrário do que ele assumiria em termos teóricos, ele não pode ser um não governo, mas uma prática refletida de governo, que se divide em dois momentos: “[...] o primeiro coincide com o desenvolvimento das teorias da 'razão de Estado', ao passo que o segundo corresponde à formação da 'Economia política', núcleo da racionalidade política liberal” (ADVERSE, 2014, p. 17). O liberalismo encontra sua motivação inicial e mais profunda na necessidade de governar a conduta, não simplesmente na luta pelo reconhecimento e respeito aos direitos fundamentais dos indivíduos, mas na criação, incitação e manipulação de liberdades por meio de mecanismos de segurança e governo ${ }^{7}$.

Justamente por não ser o objetivo do liberalismo uma limitação das ações de governo de modo a promover a liberdade e a essência humana, mas um governar mais profundo e coeso das sociedades modernas, Sven Opitz (2011) e Susanne Krasmann (2011) analisam a questão do governo “liberal” pelas práticas locais de segurança, expondo que o liberalismo, longe de propiciar mais liberdade, a subverte. As análises apresentadas pelos autores se dão no sentido de evidenciar as formas liberais de governo que, ao contrário do que se poderia colocar, restringem a liberdade sob o argumento de aumentá-la, legitimando-se por meio de um discurso que defende a natureza liberal do homem. Para Opitz, o Estado liberal assume o mesmo papel das teorias soberanas de outrora, sendo uma doutrina que, buscando se colocar como uma metafísica, intenta legitimar certas práticas de governo que, mesmo em total desacordo com o princípio norteador das instituições democráticas liberais (a liberdade), estão paradoxalmente a serviço delas. Com efeito, afirma Opitz que “[...] a noção e a lógica da segurança são indispensáveis se nós desejamos compreender as formas contemporâneas de práticas como as policiais de atirar-para-matar ou métodos de interrogatório envolvendo tortura” (OPITZ, 2011, p. 94).

Em um espaço de governo liberal em que os princípios universais ditam que os indivíduos devem exercer sua liberdade ante o Estado, o qual deve respeitá-la, emerge uma série de discursos que chamam a atenção para uma necessidade premente de segurança no sentido de que os indivíduos

\footnotetext{
${ }^{7}$ Mesmo que o "Estado social” tenha se interposto em meio às discussões levantadas, ainda assim a preocupação estaria centrada na questão de uma essência privada do ser humano, pois a função de um governo de bem-estar social seria a de proporcionar aos cidadãos condições para que eles pudessem ser livres. Assim, proporcionar certos tipos de "assistência” não seria, propriamente, uma mudança de paradigma em relação ao cidadão enquanto homo oeconomicus, mas uma forma de tentar atenuar os problemas que a essência econômica impõe (QUADROS, 2008, p. 36-41).
} 
possam exercer a sua liberdade. Afinal, sem segurança, a essência humana não poderia encontrar um espaço para se manifestar plenamente. Opitz e Krasmann (2011, p. 96) citam vários exemplos: em 2006 foi colocada em discussão uma proposta legislativa na Alemanha, permitindo à força aérea abater aeronaves com civis a bordo, desde que houvesse ameaça terrorista; o diretor do Escritório Federal Alemão para Proteção da Constituição, Heinz Fromm, declarou que informações advindas de fontes exteriores, mesmo extraídas mediante tortura, deveriam ser utilizadas; prisões americanas que encarceram e torturam sujeitos que ameaçam a segurança nacional.

Vale notar que neste tipo de situação, os argumentos que defendem a necessidade de tais medidas apelam para a necessidade de segurança da população, tendo em vista que "sob ameaça terrorista” ou “de uma violência urbana incontrolável” não se pode exercer a liberdade. Embora haja proibição expressa de práticas de tortura ou de ataques a civis que tomou corpo em tratados, leis, constituições e na própria autocompreensão da sociedade ocidental liberal, ainda assim discussões recentes são colocadas em pauta. Isso porque, na defesa da essência liberal humana, tem-se que qualquer medida é válida. Ou seja, tal como Cálicles apregoou, é preferível que indivíduos absolutamente livres de constrangimentos pratiquem injustiças ao darem vazão à sua vontade de potência do que sejam impostos constrangimentos à liberdade deles.

Partindo do exemplo da tortura como prática de segurança, o que estes discursos fazem é estabelecer uma diferença entre a tortura em nome da segurança (permitida) e a tortura como punição (proibida). Entretanto, as práticas de segurança populacional não se limitam a casos extremos como estes, transformando a arquitetura de estádios de futebol, estações de trem e até de cidades. Como afirma Opitz (2011, p. 95), “Em nome da segurança indivíduos abandonam suas instâncias de expectadores passivos e tornam-se parte de uma comunidade proativa vigilantemente coletando informações e tomando medidas contra perigos potenciais [...]” que infrinjam a curva de normalidade. Existe, inclusive, um portal na internet nos Estados Unidos que permite uma "guerra ao terror” interativa, na qual o cidadão pode denunciar qualquer perigo em potencial que coloque em risco a liberdade da população. Percebe-se uma guerra travada internamente à sociedade em defesa daqueles que querem exercer suas liberdades em governos liberais, ou seja, admitem-se, no âmago de um governo liberal, intervenções na esfera individual que, por mais que contradigam os preceitos universais de liberdade, operam como infrasseguranças sem qualquer incoerência formal.

Segundo Krasmann (2011, p. 116-117), os discursos que protagonizam práticas de segurança como a tortura, legalizando-a, embasam-se no fato de que eventuais ameaças extraordinárias requerem medidas extraordinárias. O exemplo clássico é o de uma pessoa que sabe onde está uma bomba, surgindo a questão da possibilidade de se torturá-la para conseguir a informação, com a 
intenção de salvar outras vidas. Aparentemente uma lei que regulamente esta questão não leva, necessariamente, à normalização das práticas de tortura, uma vez que o sistema soberano legal, como um todo, permanece coeso, persistindo os princípios de uma democracia liberal soberana parlamentar. Entretanto, para Agamben (apud KRASMANN, 2011), essas certezas são dubitáveis:

O “estado de exceção”, ele argumenta (com seu ponto de partida sendo Carl Schmitt), é um elemento integral da lei. Não é uma resposta a uma situação caótica precedendo uma ordem jurídica, mas, ao contrário, o resultado de uma suspensão da norma para que ela possa continuar coesa - a lei é revogada através da lei. O estado de exceção não marca uma zona além da lei, mas uma legalidade definida como zona, onde a norma está suspensa, dando ao poder soberano acesso direto à “vida nua” (KRASMANN, 2011, p. 117).

Assim, Agamben situa o estado de exceção não como algo inscrito no poder soberano, mas como um recurso eventual das sociedades liberais democráticas. Todavia, a perspectiva de Foucault parece destoar um pouco, na medida em que sua noção de governamentalidade é separada, em certa medida, da lógica da lei e do poder soberano. Diferentemente de Agamben, Krasmann não concebe práticas de segurança como a tortura como um meio de o poder soberano obter acesso à vida biológica no momento de suspensão da lei e da constitucionalidade. "Ao invés disso, a tortura circunscreve-se no horizonte operacional de um governo liberal em nome da segurança - e produz lei ao longo deste caminho” (KRASMANN, 2011, p. 117).

Discursos de segurança apontam para uma ilimitação e multiplicação das tecnologias de governo populacional, implicando, com isso, uma erosão de distinções como legal/ilegal, privado/público, civil/militar. Assim, em nome da proteção da liberdade (atributo universal), inúmeras práticas locais que a contradizem são empregadas. Logo, por mais que a democracia liberal seja afetada por um profundo paradoxo, como uma prática de governo que limita e possibilita o governo, a tese de Foucault (apud ADVERSE, 2014) é a de que o liberalismo é uma prática refletida de governo que, como tal, governa a população e não possibilita um espaço de não intervenção aos indivíduos em que eles possam se realizar enquanto seres dignos e absolutamente iguais (ADVERSE, 2014, p. 17). Em outras palavras, práticas de segurança locais de governos liberais são o avesso da democracia, pois, ainda que seus mecanismos sejam capazes de coexistir com os ideais modernos democráticos (já que atuam em instâncias distintas), direitos e liberdades fundamentais e individuais são deturpados, visto que operam mecanismos contrários ao direito igualitário (MONOD, 1997, p. 64-65).

Portanto, o traço mais importante da governamentalidade liberal foi assegurar o jogo complexo dos interesses e garantir a liberdade para que este jogo se desenrolasse, buscando produzir e organizar a liberdade [...]. A governamentalidade possuía seu funcionamento atrelado à necessidade de determinar em que medida os interesses e as liberdades individuais 
constituíram um perigo para o interesse de todos [...]. O objetivo central da governamentalidade foi garantir um mecanismo de segurança que fornecesse mecanismos e modos de intervenção estatal, cuja função era promover a segurança do processo natural, de processos econômicos e dos processos intrínsecos à população. A liberdade foi um elemento indispensável da governamentalidade (SILVEIRA, 2005, p. 101-102).

Foucault evidencia que a governamentalidade liberal, ao contrário do que sustenta a história convencional, não consiste meramente em um respeito ao particular, aos direitos dos indivíduos e à liberdade como um processo capaz de se manifestar naturalmente. Em vez disso, a proposta do filósofo é a de que o liberalismo descobre e adota uma lógica imanente capaz de gerar uma aparência de ordem. A suposta liberdade natural da espécie humana é, na verdade, constituída no âmbito da artificialidade política das relações de poder. Ao tomar a população como uma entidade física detentora de regularidades naturais imanentes, a atividade governamental não deve dificultar os processos naturais, mas aliar-se a eles de modo a ampliar suas dinâmicas e possibilidades para que a população se torne produtiva (OPITZ, 2011, p. 97-98). Nos termos de Adverse,

\begin{abstract}
Se, de um lado, o efetivo exercício do poder do Estado moderno é informado pelas técnicas de condução, por outro, ele dará ensejo a uma elaboração conceitual. Isto significa que a governamentalidade se constitui também como uma "prática refletida de governo" cuja história pode ser dividida em dois momentos: o primeiro coincide com o desenvolvimento das teorias da "razão de Estado", ao passo que o segundo corresponde à formação da "Economia política”, núcleo da racionalidade política liberal (ADVERSE, 2014, p. 16-17).
\end{abstract}

Noutros termos, sob a aparência de não governar, a governamentalidade liberal governa.

Devido a isso, a população assume postulados da economia que aparecem no campo social como leis naturais. Na medida em que esses processos serão alvos de intervenções políticas somente indiretas, há uma racionalização dos dispositivos de poder de modo a gerir as potencialidades humanas e, ainda, aparentar que a liberdade é absoluta, mas que, relembrando, constitui-se no bojo da artificialidade das relações de poder. Nesse jogo liberal, os interesses e as análises de custo tornamse os elementos centrais de uma intervenção governamental travestida de não intervenção. Por conseguinte, a posição da soberania transcendente é substituída por uma ação de governo centrada na economia política voltada para os processos naturais.

Entretanto, o próprio pressuposto de auto-organização social já pressupõe medidas interventivas, tese que se justifica pelas medidas de segurança anteriormente citadas. Para Opitz (2011), no liberalismo há uma relação paradoxal entre a intervenção e a não intervenção. Ainda para Opitz,

Por um lado, Foucault explica, o governo liberal constitui estruturas específicas de contingência nas quais se age de modo a gerir a liberdade. "Isto consome liberdade, o que significa que se deve produzi-la. Deve-se produzi-la, deve-se organizá-la.” (Foucault 2008:63). [...] Visto por estas lentes, o governo liberal evita relações destrutivas de violência 
e coerção direta. Ao invés disso, "ele incita, induz, seduz, facilita ou dificulta” (Foucault 1982:220). Correspondentemente, as tecnologias de segurança são "tecnologias ambientais” [...] que funcionam indiretamente e asseguram que os indivíduos façam uso de suas liberdades específicas. Por outro lado, as tecnologias de segurança também direcionam práticas e sujeitos que não se encaixam no jogo transacional da liberdade. Elas se focam em práticas heterogêneas, formas de conduzir e modos de ser que ameaçam corromper os “poderes da liberdade” por dentro (OPITZ, 2011, p. 99).

Assim, diante de toda uma gama de dispositivos de segurança, pode-se dizer que as tecnologias de poder que determinam o plano da governamentalidade produzem e incitam a liberdade, mas gerindo-a por intervenções indiretas. Produzem-se, compulsoriamente, medidas para assegurar o uso da liberdade em todos os lugares. Ainda Opitz (2011, p. 99-100) dirá que a questão da segurança no liberalismo é complexa porque os discursos de segurança justificam a intervenção apenas em termos de não intervenção, isto é, a intervenção governamental é necessária para que os processos nos quais não se deve intervir não sejam ameaçados. É como se a intervenção se desse apenas de modo a tornar a não intervenção possível e viável. "De acordo com a razão governamental, intervenção sempre remete à não intervenção e vice-versa. O ponto crucial é que este paradoxo não é um erro ou falha a ser dissipada [...]”, mas um mecanismo racionalizado da governamentalidade liberal que, por sua vez, nunca está fixado, sendo um processo de calibração constante de cálculos de segurança. “Os cálculos de segurança marcam o ponto de inflexão que navega entre a intervenção e a não intervenção, negociando as condições [...] de ambas” (OPITZ, 2011, p. 100).

Assim, se as práticas de segurança intervêm, justificando-se no interesse de possibilitar a liberdade, a governamentalidade responderá a questões como: quais práticas de liberdade são desejáveis? Quais são as consequências negativas possíveis? Há medidas interventivas viáveis? Quais são as fontes de perigo em potencial? De que forma e até que ponto o perigo pode ser tolerado? Como ele pode ser neutralizado? Vale a pena o custo da neutralização?

Na medida em que os dispositivos de segurança são aliáveis à expansão de modos iliberais de governo, a segurança, em última instância, inverte a liberdade dentro da máquina soberana que teria como tarefa a curatela da liberdade. Por esta razão, Foucault chama a atenção ao fato de que os mecanismos interventores do liberalismo garantem a fundamentação, a legitimação e a criação de um formidável corpo legislativo para atuar intervindo dentro do quadro geral dos preceitos globais igualitários das democracias parlamentares. A liberdade liberal não é um dado, um dogma a ser tomado como verdade, um reduto inexorável, mas aquilo com o que o poder é exercido, isto é, “[...] a contra-face do investimento político da liberdade” (ADVERSE, 2014, p. 23). Relembrando a distinção examinada por Krasmann entre Agamben e Foucault, é importante evidenciar que o pensador francês não concebe as práticas de segurança que sustentam os regimes liberais como uma 
suspensão da norma, mas, assim como a liberdade, como a contraface do investimento político democrático liberal, como se a suspensão da forma fizesse parte do aparato jurídico liberal moderno.

Logo, enquanto princípios fundamentais como a inalienabilidade dos direitos humanos impõem um controle externo à limitação do poder, critérios como a utilidade ou a necessidade de segurança têm o potencial de retirar os limites ao exercício do poder, legitimando uma luta em favor da liberdade, mas que a viola. O fato de o liberalismo adotar o critério da utilidade como princípio de valoração faz com que nenhuma instância, nem mesmo as legislações infraconstitucionais, tenha de se submeter ao critério da legitimidade. A incitação à cultura do medo como intervenção indireta, por exemplo, cria uma condição interna para intervenções no âmago da liberdade que, aparentemente, encaixam-se perfeitamente nos princípios universais democráticos.

Apenas se faz necessário ressaltar o fato de que, por mais que Foucault (2008) não limite a governamentalidade à lei e as medidas de segurança à suspensão da norma, ele não destitui a lei de sua significância histórica. Segundo Krasmann (2011), a proposta foucaultiana é a de atribuir a esta noção uma nova significância, de um instrumento de efetivação de normas e processos de normalização. A lei seria, em última instância, o instrumento por meio do qual as intervenções de governo se legitimam em vista da necessidade de segurança que a liberdade privada (do oikos) requer para se manifestar. Retornando ao exemplo da tortura, que pode ser estendido a outras medidas de segurança, uma vez que a lei deve garantir os princípios constitucionais constitutivos das democracias liberais, a racionalização da tortura com uma chancela legal de violência regulamentada, empregada apenas para acabar com a violência e possibilitar a liberdade, faz com que esse discurso seja paradoxal.

\section{CONSIDERAÇÕES FINAIS}

Na medida em que se instauram os regimes políticos não intervencionistas que asseguram direitos individuais, disso não decorre a conclusão de um Estado que se abstém de infringir a liberdade individual. De fato, com a criação e aparente efetivação de um campo jurídico no qual o Estado não pode intervir, maximizam-se as possibilidades das práticas de governo, uma vez que, a partir de quando se proíbe a ação em um campo, pode-se intervir em todos os outros. Ainda que a governamentalidade liberal deva garantir a aparência de liberdade no mercado e nos interesses individuais, pode-se intervir indiretamente nesses elementos na medida em que se intervém em todo 
o resto, fabricando-se uma aparência de liberdade e formas de sujeito a partir dos efeitos de verdade gerados pela economia política.

Assim, diante do paradoxo segundo o qual o ser humano necessita se libertar dos constrangimentos para poder exercer a sua essência, mas requer segurança para tanto, surge uma série de medidas que passam a fazer parte das democracias liberais. Afinal, é adotada a tese metafísica antropológica segundo a qual o ser humano só pode se realizar enquanto tal se não houver constrangimentos. Com isso, medidas que restringem a liberdade e negam diretamente os preceitos democráticos (como tortura, vigilância ininterrupta e prisões arbitrárias) passam a fazer parte das democracias.

\section{REFERÊNCIAS}

ADVERSE, Helton Machado. Liberdade e Governamentalidade: Foucault e a Genealogia do Liberalismo. Revista Estudos Filosóficos, número 12, 2014, p. 16-27. Disponível em: <https://goo.gl/poqTVE>. Acesso em: 10 ago. 2014.

FONSECA, Márcio Alves. Michel Foucault e o direito. São Paulo: Max Limonad, 2002.

FOUCAULT, Michel. Nascimento da biopolítica. Tradução Eduardo Brandão. São Paulo: Martins Fontes, 2008.

FRIEDMAN, Milton. Capitalism and freedom. Chicago: The University of Chicago Press, 1992.

HAYEK, F. A. O caminho da servidão. Tradução Anna Maria Capovilla, José Ítalo Stelle e Liane de Morais Ribeiro. São Paulo: Instituto Ludwig von Mises Brasil, 2010.

KRASMANN, Susanne. The Right of Government: Torture and the Rule of Law. In: BRÖCKLING, Ulrich; KRASMANN, Susanne; LEMKE, Thomas. Governmentality: Current Issues and Future Challenges. Nova Iorque: Routledge, 2011.

LAGASNERIE, Geoffroy. A última lição de Michel Foucault. Tradução Andre Telles. São Paulo: Editora Três Estrelas, 2013.

LEMKE, Thomas. Biopolitics: An advanced introduction. Nova Iorque: New York University Press, 2011.

MONOD, Jean-Claude. Foucault: La police des conduites. Paris: Éditions Muchalon, 1997.

OFFE, Claus. Problemas estruturais do estado capitalista. Tradução Bárbara Freitag. Rio de Janeiro: Tempo Brasileiro, 1984. 
OPITZ, Sven. Govern Unlimited: The Security Dispositif of Iliberal Governmentality. In: BRÖCKLING, Ulrich; KRASMANN, Susanne; LEMKE, Thomas. Governmentality: Current Issues and Future Challenges. Nova Iorque: Routledge, 2011.

PIZZORNO, Alessandro. Foucault et la conception libérale de l'individu. Michel Foucault philosophe: rencontre internationale, Paris 9, 10, II janvier 1988. Paris: Seuil/Gallimard, 1989.

PLATÃO. Górgias. Tradução, ensaio introdutório e notas Daniel R. N. Lopes. São Paulo: Editora Perspectiva, 2011.

QUADROS, José Luiz. Direito constitucional: curso de direitos fundamentais. São Paulo: Editora Método, 2008.

SAFATLE, Vladimir. Circuito dos afetos. São Paulo: Cosac Naify, 2015.

SILVEIRA, Rafael Alcadipani. Michel Foucault: poder e análise das organizações. Rio de Janeiro: Editora FGV, 2005.

WEBER, Max. A política como vocação. In: WEBER, Max. Ensaios de sociologia. Organização e introdução H. H. Gerth e C. Wright Mills. Tradução Waltensir Dutra. Rio de Janeiro: LTC - Livros Técnicos e Científicos Editora S.A., 1982.

Ricardo Manoel Oliveira Morais

Doutor em Direito pela Universidade Federal de Minas Gerais (UFMG). E-mail: ricardo_mom@hotmail.com

Adriana Campos Silva

Doutora (2002) e Mestre (1990) em Direito pela UFMG. Professora Decana da Área de Direito Constitucional. Professora na Pós-Graduação e na Graduação da UFMG. E-mail: adrilaw10@hotmail.com 